\title{
Glycation Accelerates Fibrillization of the Amyloidogenic W7FW14F Apomyoglobin
}

\author{
Clara lannuzzi ${ }^{9}$, Rosa Maritato ${ }^{\text {, Gaetano Irace, Ivana Sirangelo* }}$ \\ Department of Biochemistry, Biophysics and General Pathology, Second University of Naples, Naples, Italy
}

\begin{abstract}
Neurodegenerative diseases are associated with misfolding and deposition of specific proteins, either intra or extracellularly in the nervous system. Advanced glycation end products (AGEs) originate from different molecular species that become glycated after exposure to sugars. Several proteins implicated in neurodegenerative diseases have been found to be glycated in vivo and the extent of glycation is related to the pathologies of the patients. Although it is now accepted that there is a direct correlation between AGEs formation and the development of neurodegenerative diseases, several questions still remain unanswered: whether glycation is the triggering event or just an additional factor acting on the aggregation pathway. To this concern, in the present study we have investigated the effect of glycation on the aggregation pathway of the amyloidogenic W7FW14F apomyoglobin. Although this protein has not been related to any amyloid disease, it represents a good model to resemble proteins that intrinsically evolve toward the formation of amyloid aggregates in physiological conditions. We show that D-ribose, but not D-glucose, rapidly induces the W7FW14F apomyoglobin to generate AGEs in a time-dependent manner and protein ribosylation is likely to involve lysine residues on the polypeptide chain. Ribosylation of the W7FW14F apomyoglobin strongly affects its aggregation kinetics producing amyloid fibrils within few days. Cytotoxicity of the glycated aggregates has also been tested using a cell viability assay. We propose that ribosylation in the W7FW14F apomyoglobin induces the formation of a cross-link that strongly reduces the flexibility of the $\mathrm{H}$ helix and/or induce a conformational change that favor fibril formation. These results open new perspectives for AGEs biological role as they can be considered not only a triggering factor in amyloidosis but also a player in later stages of the aggregation process.
\end{abstract}

Citation: lannuzzi C, Maritato R, Irace G, Sirangelo I (2013) Glycation Accelerates Fibrillization of the Amyloidogenic W7FW14F Apomyoglobin. PLoS ONE 8(12): e80768. doi:10.1371/journal.pone.0080768

Editor: Annalisa Pastore, National Institute for Medical Research, Medical Research Council, London, United Kingdom

Received August 9, 2013; Accepted October 4, 2013; Published December 4, 2013

Copyright: (c) 2013 lannuzzi et al. This is an open-access article distributed under the terms of the Creative Commons Attribution License, which permits unrestricted use, distribution, and reproduction in any medium, provided the original author and source are credited.

Funding: This work was supported by grants from Regione Campania (DGR 2270, Dec 30th, 2006). The funder had no role in study design, data collection and analysis, decision to publish, or preparation of the manuscript.

Competing Interests: The authors have declared that no competing interests exist.

*E-mail: ivana.sirangelo@unina2.it

9 These authors contributed equally to this work.

\section{Introduction}

Protein misfolding and subsequent aggregation underlies several neurodegenerative diseases such as Alzheimer's, Huntington's and Parkinson's disease. It is now stated that any failure of a specific protein/peptide to fold/unfold correctly or to remain properly folded is at the basis of these pathological conditions characterized by the presence of deposits of ordered protein aggregates in the affected tissues [1,2]. These structures are generally described as amyloid fibrils and the related diseases are known as amyloid diseases. Typically, the fibrils are long polymeric assemblies of 2 $10 \mathrm{~nm}$ wide, with a core region formed by repetitive arrays of $\beta$ sheets oriented perpendicularly to the fibril axis forming the so called cross- $\beta$ structure $[3,4]$. The aggregation reaction has been well characterized in vitro. Amyloid fibrils formation occurs through a nucleation-dependent polymerization process consisting of two phases: nucleation and extension. Nucleus formation requires a series of association steps within monomers, which are thermodynamically unstable, representing the rate-limiting step (lag phase). Once a nucleus has been formed, further addition of monomers to the nuclei becomes thermodynamically favored, resulting in a rapid extension of amyloid fibrils in vitro [5]. For years, the fibrils have been considered responsible for the toxicity associated with the amyloidosis. However, it is widely accepted that the non-fibrillar assemblies and, in particular, the oligomeric forms play a key role in the amyloid cytotoxicity. These aggregates populate the early stages of the growth phase preceding the protofibrils formation and are the main responsible of membrane homeostasis disruption [3,6-9]. The oligomers are small, flexible and usually globular species but maintain the essential amyloid features $[4,8,10]$. These intrinsic properties can explain their cytotoxicity, indeed the reduced size and the spherical shape make them able to interact with the cellular membrane causing cellular dysfunction eventually triggering apoptosis $[6,9]$.

Protein found aggregated in pathological conditions do not share any sequence identity or structural homology and considerable heterogeneity also exists for secondary structure composition and chain length. Moreover, an increasing number of proteins with no link to protein deposition diseases has been found to form, under extreme conditions in vitro, fibrillar aggregates that have the same morphological, structural, and tinctorial properties of the amyloid fibrils [11-14]. These findings suggest that protein aggregation may be a generic property of the polypeptide backbone and independent of a specific amino acid sequence. In addition, it has been shown that even the toxic effects of protein 
aggregates, mainly in their pre-fibrillar organization, result from common structural features rather than from the presence of specific side chains. Myoglobin belongs to this class of proteins, being able to aggregate and form amyloid fibrils under appropriate experimental conditions $[15,16]$. In particular, the replacement of both indole residues located at positions 7 and 14 in the $\mathrm{N}$ terminal region with phenylalanine (W7FW14F) renders myoglobin highly susceptible to aggregation and able to form amyloid fibrils under physiological conditions of $\mathrm{pH}$ and temperature [1619]. Similarly to other amyloidogenic proteins, the cytotoxicity of the W7FW $14 \mathrm{~F}$ apomyoglobin aggregates is associated to the early oligomers intermediates rather than mature fibrils [20-22]. These features make the W7FW14F myoglobin a suitable model for studying the molecular mechanisms underlying amyloid aggregation under physiological conditions. Indeed, this amyloidogenic protein allows performing measurements without the interference of denaturing agents and this is certainly more advantageous than other protein systems that need to be partially unfolded by a variety of denaturing agents.

Although the aggregation process of amyloidogenic proteins has been widely studied in vitro and many physiological (environmental and genetic) factors involved have been identified, the molecular mechanisms underlying the formation of aggregates in vivo and in pathological conditions are still poorly understood. The majority of cases of neurodegenerative diseases are sporadic, suggesting that other factors must contribute to the onset and progression of these disorders. Post-translational modifications are known to affect protein structure and function. Some of these modifications might affect proteins in detrimental ways and lead to their misfolding and accumulation. Reducing sugars play important roles in modifying proteins, forming advanced glycation end-products (AGEs) in a non-enzymatic process named glycation.

Proteins in amyloid deposits are often glycated suggesting a direct correlation between protein glycation and amyloidosis [2327]. Glycation reactions are common to all cell types: glycated products slowly accumulate in vivo leading, besides cellular modifications involved in the aging process, to several different protein dysfunctions [28-31]. Glycation is a stepwise process that begins with a nucleophilic addition reaction between a free amino group of a protein and a carbonyl group from a reducing sugar, forming a reversible intermediate product (Schiff's base). The Schiff's base can turn into a stable ketoamine by Amadori rearrangement. The following step is the formation of several intermediate products, some of them very reactive. The final step consists of a crosslink formation between products in which heterogeneous structures (AGEs) are formed [32].

Recently, a great attention has been paid to protein glycation as a possible factor involved in protein aggregation [33-36]. AGEs and their precursors (methylglyoxal and glyoxal) have been found to promote aggregation and cytotoxicity of insulin and intracellular amyloid-beta carboxy-terminal fragments [37,38]. Human $\beta 2$-microglobulin is rapidly glycated in the presence of D-ribose, forming highly toxic granular aggregates [39]. Recent studies have also shown that bovine serum albumin (BSA), $\alpha$ - synuclein and tau protein form globular amyloid-like aggregates upon glycation with D-ribose [40-42].

All these proteins, if not glycated, are soluble and not prone to aggregation in the experimental conditions used thus suggesting that protein glycation can trigger amyloid aggregation. However, several questions remain unanswered, whether glycation is the triggering event or just an additional factor acting on the aggregation pathway. Glycation may then represents a strong contributor to amyloid aggregation by accelerating or stabilizing pathological protein aggregates rather than promoting the aggregation process. To this concern, in the present study we have investigated the effect of glycation on the aggregation pathway of the W7FW14F apomyoglobin. Although this protein has not been related to any amyloid disease, it represents a good model to resemble proteins that intrinsically evolve toward the formation of amyloid aggregates. We show that AGEs formation strongly accelerates the amyloid fibrils formation in the W7FW $14 \mathrm{~F}$ apomyoglobin providing evidences on the effect of glycation as an additional and not only an inducer factor in amyloid aggregation.

\section{Results and Discussion}

\section{Glycation of the W7FW14F apomyoglobin}

To check whether the apomyoglobin mutant W7FW14F can be glycated in vitro, the protein was incubated with $0.5 \mathrm{M}$ D-ribose and $0.5 \mathrm{M} \mathrm{D}$-glucose alternatively and samples were analyzed at different time points. It is known that glycation of a protein results in the formation of a new fluorescent derivative $\left(\lambda_{\text {ex }} 320 \mathrm{~nm}, \lambda_{\text {em }}\right.$ $410 \mathrm{~nm}$ ) and thus fluorescence is commonly used to monitor the formation of AGEs. Changes in fluorescence at $410 \mathrm{~nm}$ were measured at different time intervals (days) (Figure 1A). The emission intensity of ribosylated W7FW14F apomyoglobin increased markedly with incubation time. At the same time glucosylated and untreated protein did not show a marked increase in fluorescence under the experimental condition used. This demonstrates that W7FW14F apomyoglobin undergoes glycation in vitro and that D-ribose is much more efficient than D-glucose in promoting the process. Higher concentrations of sugar were also tested (up to $1.0 \mathrm{M}$ ) but no significant differences were observed on protein glycation kinetics (data not shown).

Glycation is a non-enzymatic process in which proteins react with reducing sugar molecules. Usually the reaction occurs between the $\alpha$-amino group of the $\mathrm{N}$-terminal amino acid or the $\varepsilon$-amino groups of lysines and the aldehyde or keto group of the reducing sugar. The stronger glycating ability of D-ribose can be due to the fact that its pentose ring is not planar but occurs in one of a variety of conformations, generally described as "puckered", which make the unstable aldofuranose ring more sensitive to reactions with amino groups. For this reason, among the reducing sugars, D-ribose is probably the most reactive in the glycation of proteins [43-44].

Besides lysine residues, glycation has also been found on the side chains of arginines and histidines [45]. To check whether the fluorescence at $410 \mathrm{~nm}$ was resulting from the reaction of D-ribose with lysine residues we looked at the emission signal at $425 \mathrm{~nm}$, typical of a glycated lysine (Figure 1B). The strong parallelism between the emission at 410 and that at $425 \mathrm{~nm}$ suggests that the fluorescent derivative results from the reaction of D-ribose with $\varepsilon$ amino groups of the lysine side chain on the protein [42]. As shown in Figure 1, the W7FW14F apomyoglobin resulted highly glycated after 5 days of incubation with $0.5 \mathrm{M}$ D-ribose and reached a maximum after 10 days. Generally, the glycation process that induces AGEs formation requires a long time (days) depending both on glycating agents and experimental conditions. The observed lag phase (2-5 days) is the result of complex chain reactions that eventually lead to the AGEs formation detected [46]. A very similar time course has been observed for the wildtype protein in analogous experimental conditions [50].

In summary, these results show that D-ribose, but no D-glucose, rapidly induces the W7FW $14 \mathrm{~F}$ apomyoglobin to generate AGEs in a time-dependent manner and protein ribosylation is likely to involve lysine residues on the polypeptide chain. 

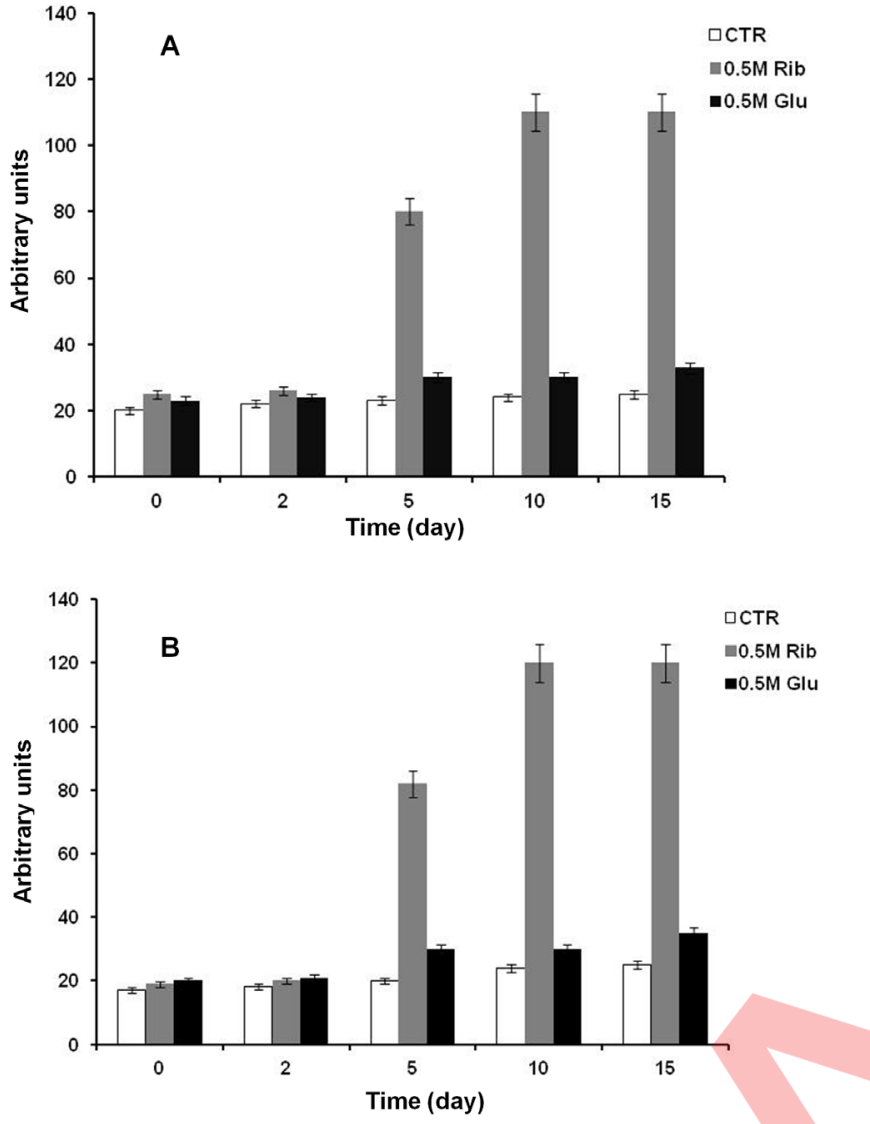

Figure 1. Glycation of the W7FW17F apomyoglobin. Protein glycation monitored by fluorescence spectroscopy. W7FW14F apomyoglobin was incubated in the absence (white bar) and in the presence of $0.5 \mathrm{M}$ D-ribose (grey bar) and 0.5 M D-glucose (black bar) and changes in maximal fluorescence intensity were monitored at different time intervals. Protein concentration was $40 \mu \mathrm{M}$, other experimental details are described in the Materials and Methods section. (A) Maximal fluorescence intensity recorded at $410 \mathrm{~nm}$ upon excitation at $320 \mathrm{~nm}$. (B) Maximal fluorescence intensity recorded at $425 \mathrm{~nm}$ upon excitation at $370 \mathrm{~nm}$. The average value ( \pm SD) of a quadruplicate experiment is plotted.

doi:10.1371/journal.pone.0080768.g001

\section{Glycation affects amyloid aggregation kinetics of the W7FW14F apomyoglobin}

To investigate the effect of glycation on the aggregation process of the W7FW14F apomyoglobin, we incubated the protein solution in the presence and in the absence of D-ribose to monitor its effect on protein aggregation at various incubation time intervals (days). This time we did not perform the experiment in the presence of D-glucose as no significant effect on protein glycation had been previously observed. Samples taken at different time points were first analyzed by western-blot analysis using a myoglobin monoclonal antibody. As shown in Figure 2A the antibody recognized apomyoglobin monomer, dimer, trimer and larger aggregates. In the absence of ribose (left panel) we observed, besides monomers, small aggregates (mainly dimers and trimers) at 2 and 5 days of incubation; higher aggregates were present only after 10 days of incubation. In the presence of $0.5 \mathrm{M}$ D-ribose (right panel) we observed higher aggregates already after 5 days of incubation indicating that protein ribosylation stimulates aggregation in the W7FW14F apomyoglobin mutant. Indeed, all protein samples were also tested using an anti-AGEs antibody

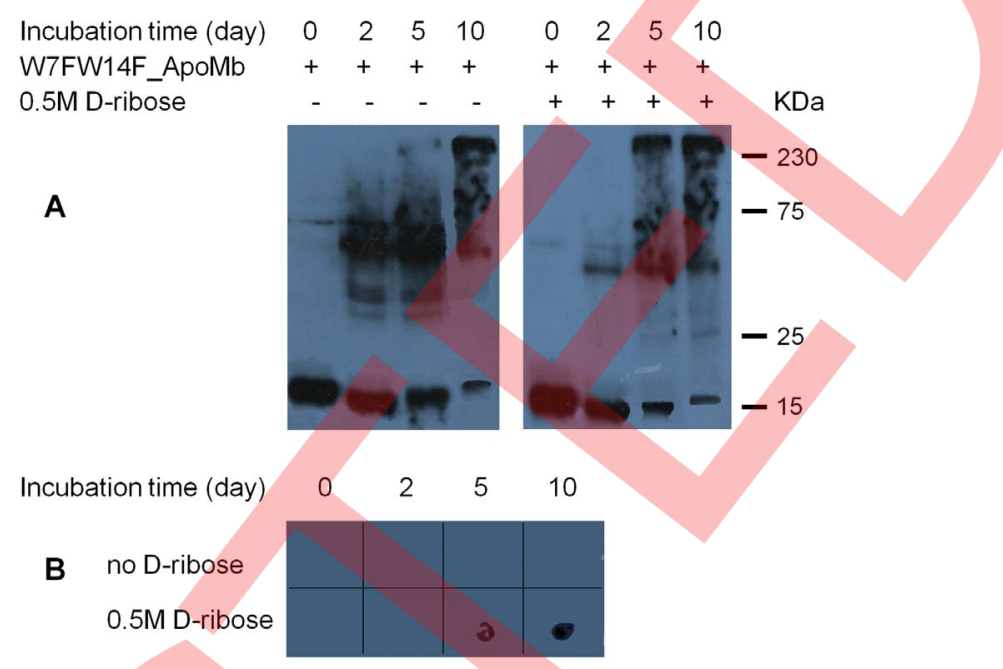

Figure 2. Western blot of ribosylated W7FW17F apomyoglobin. W7FW14F apomyoglobin was incubated in the absence and in the presence of 0.5M D-ribose and aliquots were taken at different time intervals. (A) Western blot analysis using an anti-myoglobin antibody. (B) Dot blot analysis using an anti AGE antibody. Experimental conditions are described in the Materials and Methods section. doi:10.1371/journal.pone.0080768.g002

through a dot-blot analysis (Figure 2B). The results confirmed that aggregates formed in the presence of D-ribose at this time interval (5 days) are highly glycated thus proving a direct correlation between AGEs formation and higher aggregation in the W7FW14F apomyoglobin.

In order to understand if aggregates formed in the presence of D-ribose were amyloidogenic we tested the Thioflavine $\mathrm{T}$ (ThT) reactivity of the samples incubated in the presence and in the absence of 0.5 M D-ribose at different time intervals (Figure 3). ThT fluorescence is a widely used method for detecting amyloid formation as ThT specifically binds the fibrillar cross- $\beta$ structure and its fluorescence intensity is proportional to the amount of fibrils present $[47,48]$. The amyloidogenic W7FW14F apomyoglobin forms amyloid fibrils in at least 9-10 days from the onset of aggregation and after a lag-phase lasting 4-5 days [17,19]. As shown in Figure 3, aggregates formed in the presence of 0.5 M Dribose are clearly amyloidogenic giving a strong ThT fluorescence increase. In addition to this, samples incubated with D-ribose showed marked fluorescence emission intensity already after 5 days from the onset of aggregation. As expected, at this time point only little fluorescence typical of the lag phase was observed for the non ribosylated sample. The results indicate that glycation of the W7FW14F apomyoglobin dramatically accelerates its aggregation process promoting amyloid fibrils formation.

We have also investigated the effect of glycation on the structure of the apomyoglobin mutant at the early stages of the aggregation process following the time dependence of the far-UV CD spectrum in the absence and in the presence of $0.5 \mathrm{M}$ D-ribose (Figure 4). CD spectra were recorded immediately after $\mathrm{pH}$ neutralization of the protein samples. During the first hours of observation, for both samples, we did not observe any change in the CD spectra, all showing two minima at 208 and $222 \mathrm{~nm}$, characteristic of the $\alpha$ helical structure. The only variation recorded in time was a gradual reduction in the signal intensity due to the increase of the light scattering caused by protein aggregation [18]. The signal reduction was faster for samples incubated with D-ribose (Fig. 4B). These results suggest that the presence of ribose, in the early stage of the aggregation process, does not promote any conformational 


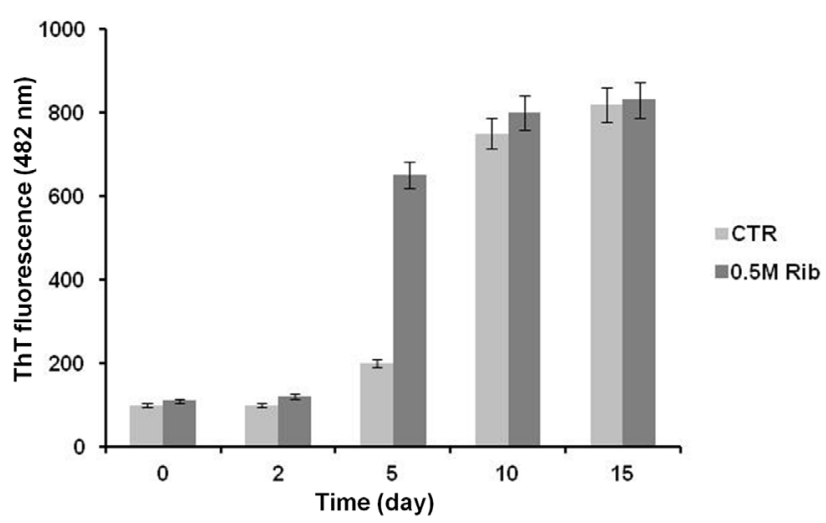

Figure 3. Effect of ribosylation on the amyloid formation for the W7FW17F apomyoglobin. W7FW14F apomyoglobin $(40 \mu \mathrm{M})$ was incubated in the absence (light gray bar) and in the presence of 0.5M D-ribose (dark grey bar) and aliquots of each sample at different incubation time intervals were monitored by ThT fluorescence. The average value $( \pm S D)$ of a quadruplicate experiment is plotted. doi:10.1371/journal.pone.0080768.g003

change in the apomyoglobin mutant but only affects its aggregation rate. The higher aggregation propensity in the presence of D-ribose could be due to local rearrangements that make protein molecules more prone to associate.

Using electron microscopy we also examined the morphology of the W7FW14F apomyoglobin aggregates produced in the absence
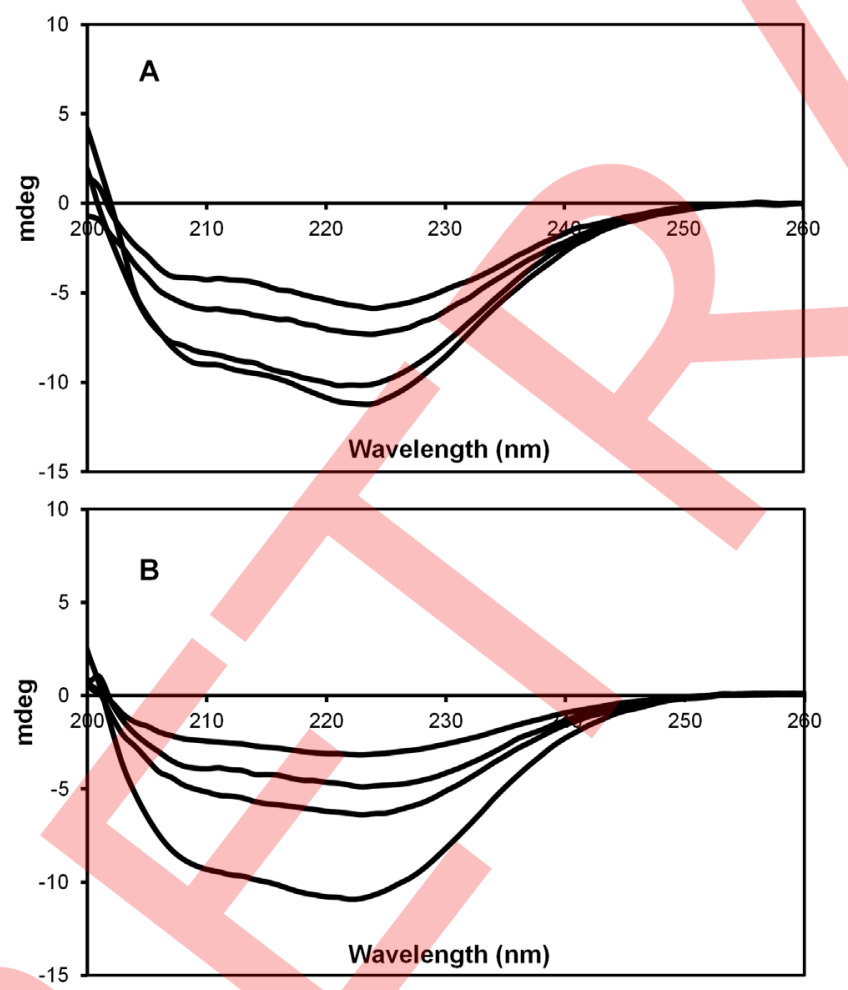

Figure 4. Effect of ribosylation on the $C D$ activity of the W7FW17F apomyoglobin. Time dependence of the far-UV CD activity of the amyloid forming W7FW14F apomyoglobin mutant at $\mathrm{pH} 7.0$ in the absence (A) and in the presence of $0.5 \mathrm{M}$ D-ribose (B). From the lower to the upper spectrum, times are: 1, 60, 180, and $360 \mathrm{~min}$. Protein concentration was $20 \mu \mathrm{M}$.

doi:10.1371/journal.pone.0080768.g004 and in the presence of $0.5 \mathrm{M}$ D-ribose at aggregation onset and 5 days thereafter (Figure 5). As expected only pre-fibrillar species were observed at the beginning of the aggregation process for both samples (Fig. 5, A and C panel). Consistent with the ThT staining, the EM images recorded 5 days from the onset of aggregation revealed the presence of mature fibrils only in the presence of $\mathrm{D}$ ribose (Fig. 5, D panel). The size of the amyloid fibrils formed with D-ribose after 5 days of incubation is comparable with that one of the mature fibrils obtained, without sugar, only after 10-14 days of maturation $[18,19]$. As shown in Figure 1, aggregates formed in the presence of D-ribose at this time interval ( 5 days) are highly glycated thus proving a direct correlation between ThT reactivity, fibril morphology (EM) and AGEs formation. In summary, these results show that ribosylation of the W7FW14F apomyoglobin strongly affects its aggregation kinetics producing mature amyloid fibrils within $2-5$ days from the onset of aggregation.

\section{Putative ribosylation sites on the W7FW14F apomyoglobin}

Recently, it has been shown that wild-type myoglobin can be glycated in vitro causing heme loss and formation of an intramolecular cross-link that is independent of heme binding. The reaction is only observed for ribose-containing sugars and the cross-link involves the $\mathrm{N}$-terminus of the protein and its neighboring Lys 133 [49,50].

In a previous study we have identified the solvent accessible regions in the W7FW $14 \mathrm{~F}$ apomyoglobin mutant through controlled proteolysis experiments in conjunction with MALDI-MS analysis of the generated fragments $[51,52]$. Results were also performed on the wild-type protein and comparison between the two proteins are summarized in Figure 6. Proteolytic experiments on W7FW14F apomyoglobin revealed that, helices $\mathrm{A}, \mathrm{D}$, and $\mathrm{E}$ are protected from protease action (in white) while helices B, C, F, $\mathrm{G} \mathrm{H}$ and their connecting loops were not protected from protease action and, thus, are exposed to the solvent (in grey). As in the wild-type protein, the $\mathrm{H}$ helix of the W7FW14F apomyoglobin is solvent exposed and thus is reasonable to suppose that Lys 133 is susceptible to glycation allowing the formation of a cross-link between the N-terminus and its side chain. Obviously, we cannot exclude that the W7FW14F mutant, having more accessible regions compared to the wild-type protein, can be glycated on additional sites too.

The same analysis performed on the W7FW14F apomyoglobin fibrils revealed that helices A, B, and E and part of D and G are involved in the fibril core (Figure 7, shown in blue) while helices C, D, F and $\mathrm{H}$ are exposed to the solvent (Figure 7, shown in red). We speculate that formation of a cross-link between the $\mathrm{N}$ terminus and the side chain of Lys133 in the W7FW14F apomyoglobin could strongly reduce the flexibility of the $\mathrm{H}$ helix and/or induce a conformational change that favor fibril formation. This can help to rationalize why AGEs formation in the W7FW14F apomyoglobin strongly accelerates its fibrillogenesis process although further analysis is needed to clarify the molecular determinants.

\section{Effect of ribosylation on the cytotoxicity of the W7FW14F apomyoglobin}

We then assessed the cytotoxicity of the W7FW14F apomyoglobin aggregates obtained in the presence of D-ribose using the MTT assay, which is a rapid and sensitive indicator of the amyloid-mediated toxicity. The toxicity of amyloid aggregates is closely linked to the presence of oligomeric species; in fact, decreased levels of MTT reduction are usually detected in the 

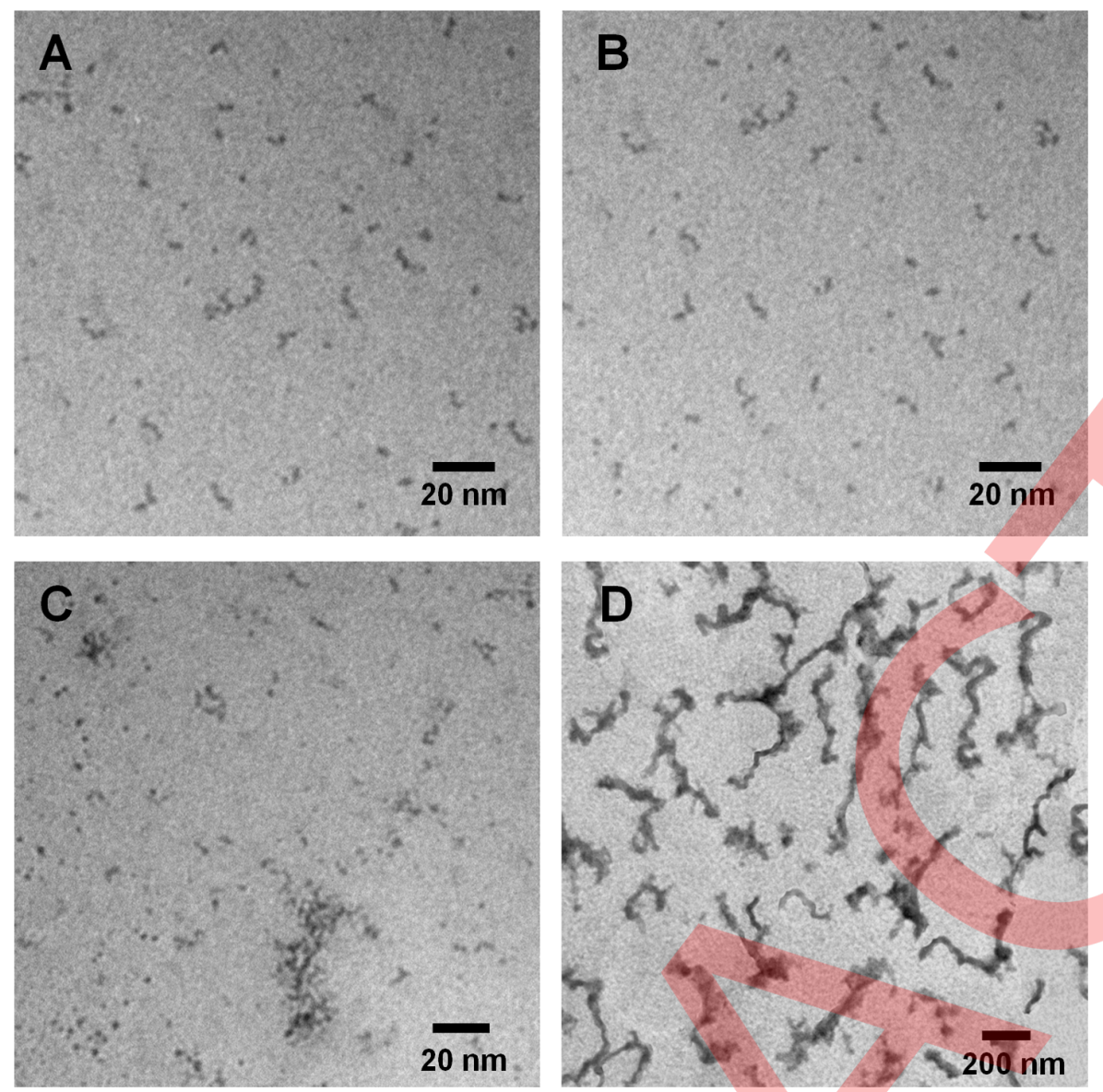

Figure 5. Effect of ribosylation on the morphology of the W7FW17F apomyoglobin aggregates. Electron microscopy images of the W7FW14F apomyoglobin in the absence of D-ribose at the beginning (A) and after 5 days of incubation (B), and in the presence of D-ribose at the beginning (C) and after 5 days of incubation (D). Experimental conditions are described in the Materials and Methods section.

doi:10.1371/journal.pone.0080768.g005

presence of soluble prefibrillar oligomers but not fibrils [53]. Similarly to other amyloidogenic proteins, the cytotoxicity of W7FW14F apomyoglobin aggregates lies not in the mature fibrils but rather in the early oligomers intermediates $[17,20]$.

We compared the toxicity of aggregates formed in the absence and in the presence of $0.5 \mathrm{M}$ D-ribose at aggregation onset and 5 and 10 days thereafter. As expected, in the absence of D-ribose, early prefibrillar aggregates ( 0 and 5 days) strongly affected cell viability (about 40\% MTT reduction), whereas fibrillar aggregates (10 days) did not (Figure 8) in accordance with previous studies [20,22]. Conversely, aggregates formed in the presence of D-ribose

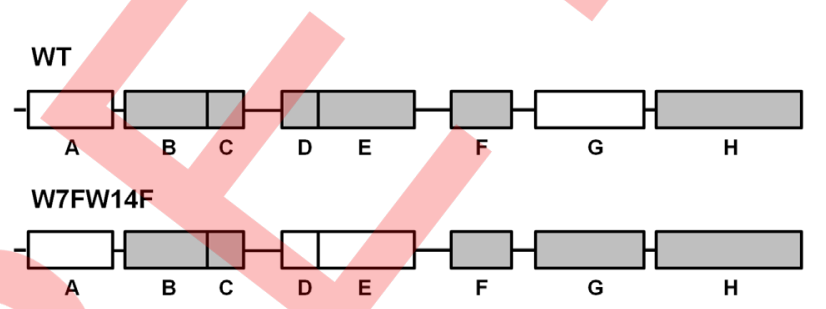

Figure 6. Solvent accessible regions in the wild-type and W7FW17F apomyoglobin. Schematic representation of the $\mathrm{A}-\mathrm{H}$ helices in the wild-type and W7FW14F apomyoglobin. Solvent accessible helices for both protein are shown in grey. Experimental conditions are described in [51].

doi:10.1371/journal.pone.0080768.g006 after 5 days of incubation did not affect cell viability supporting our finding that D-ribose induces rapid formation of harmless fibrillar aggregates. However, we can not exclude that glycated protein are not toxic at all.

Ribosylation of amyloidogenic proteins could, then, be considered a protecting factor as it stabilizes the harmless form of amyloid aggregates. On the other hand, AGEs are known to bind the cell surface receptor RAGE (the receptor for advanced glycation end products) triggering multiple intracellular signaling pathways that promote a series of physiological and pathological processes [54].

\section{Conclusions}

D-ribose is a naturally occurring pentose monosaccharide present in all living cells and their microenvironments and is a key component of numerous biomolecules involved in many important metabolic pathways. It also participates in the glycation of proteins producing advanced glycation end products (AGEs) that lead to cell dysfunction and death. Recently ribosylation in proteins has been associated to amyloidosis as it promotes protein aggregation.

It was our goal to investigate the effect of AGEs formation on proteins that naturally evolve to amyloid aggregates to test their role on the process while it is "in progress". We have chosen a protein model not related to any disease but able to form 


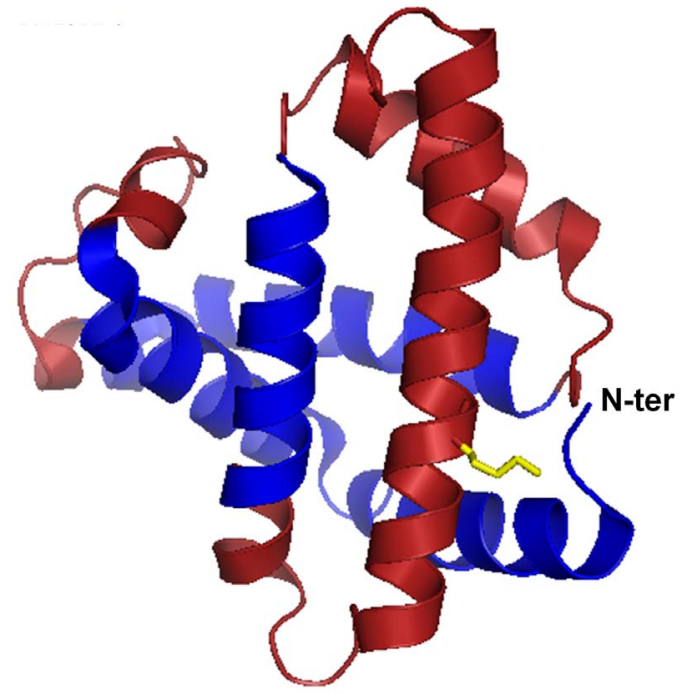

Figure 7. Proposed cross-linking in the glycated W7FW17F apomyoglobin. Structural representation of the W7FW14F apomyoglobin modeled on the wild-type protein X-ray structure ( $\mathrm{pdb} 2 \mathrm{JHO}$ ). Regions involved in the fibril core are shown in dark blue while solvent accessible regions are shown in red. Glycation is likely to promote a cross-linking between the $\mathrm{N}$-terminus and the side chain of Lys 133 (shown in yellow). The results are visualized using PyMol (The PyMOL Molecular Graphics System, Version 1.5.0.4 Schrodinger, LLC). doi:10.1371/journal.pone.0080768.g007

amyloid aggregates under physiological conditions of $\mathrm{pH}$ and temperature. We show that the protein is ribosylated during its aggregation process and that the AGEs formation rapidly induces amyloid fibrils formation. We can conclude that the AGEs formation is not necessarily the triggering event in amyloid formation but it can actively participate to the process affecting the reaction kinetics. These results open new perspectives for AGEs biological role as they can be considered not only an inducer factor in amyloidosis but also a player in later stages of the aggregation process.

\section{Materials and Methods}

\section{Materials}

Thioflavin T (ThT), 3-(4,5-dimethylthiazol-2-yl)-2,5-diphenyltetrazolium bromide (MTT), D-Ribose, D-glucose were purchased from Sigma (Sigma-Aldrich Co., St. Louis, MO). All other chemicals were of analytical grade.

\section{Protein purification}

W7FW14F apomyoglobin mutant was expressed and purified essentially as described elsewhere [16]. Briefly, the protein was expressed in the Escherichia coli M15 [pREP4] strain as Nterminal His-tagged form and then purified via affinity chromatography on $\mathrm{Ni}^{2+}$ nitrilotriacetic-acid resin (Qiagen) in denaturing conditions [55-56]. Protein purity was checked by SDSPAGE analysis. Refolding was achieved by removing denaturant by dialysis against $10 \mathrm{mM} \quad \mathrm{NaH}_{2} \mathrm{PO}_{4}, \mathrm{pH} 2.0$, containing decreasing concentrations of urea. The $\mathrm{pH}$ of the protein solution was then adjusted at neutrality. Protein concentration was determined under denaturing conditions, and absorption was measured at $275 \mathrm{~nm}$. The molar extinction coefficient at $275 \mathrm{~nm}$ calculated from tyrosine content was $3750 \mathrm{M}^{-1} \mathrm{~cm}^{-1}$.

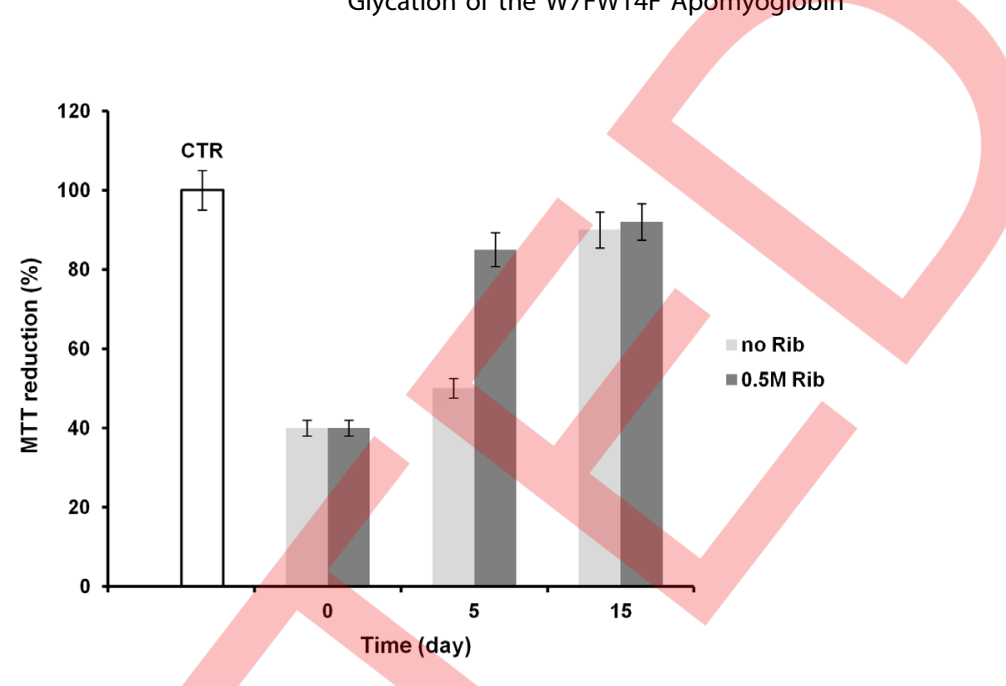

Figure 8. Effect of ribosylation on the cytotoxicity of the W7FW17F apomyoglobin aggregates. $\mathrm{NIH}-3 \mathrm{~T} 3$ cells were exposed to aggregates formed in the absence (light grey) and in the presence of D-ribose (dark grey). Aliquots of protein were taken at 0, 5 and 15 days from the onset of aggregation and incubated for $24 \mathrm{~h}$ with cells. Data are expressed as average percentage of $M T T$ reduction \pm SD relative to cell treated with medium alone or medium plus $D$-ribose, from triplicate wells from 5 separate experiments $(p<0.01)$. The white bar represents the negative control (cells treated with medium plus $0.25 \mathrm{M}$ D-ribose). Other experimental conditions are described in the Materials and Methods section.

doi:10.1371/journal.pone.0080768.g008

\section{Preparation of glycated protein}

W7FW14F apomyoglobin $\mathrm{pH} 4.0$ at a final concentration of $40 \mu \mathrm{M}$ was mixed with 0.5 and $1.0 \mathrm{M}$ D-ribose in $20 \mathrm{mM}$ $\mathrm{NaH}_{2} \mathrm{PO}_{4}$ buffer $(\mathrm{pH} 4.0)$. Protein aggregation was initiated by raising the $\mathrm{pH}$ to 7.0 and protein solution was incubated at $37^{\circ} \mathrm{C}$ for different time intervals. W7FW14F apomyoglobin alone without D-ribose and D-ribose alone were used as controls. All solutions were passed through a $0,22-\mu \mathrm{m}$ filter before use to remove insoluble particles.

\section{Fluorescence measurements}

To assess the fluorescence of AGEs, ribosylated W7FW14F apomyoglobin at a final concentration of $5 \mu \mathrm{M}$ was monitored on a Perkin Elmer Life Sciences LS 55 spectrofluorimeter. Wavelengths $\left(\lambda_{\text {ex }} 370 \mathrm{~nm} / \lambda_{\text {em }} 425 \mathrm{~nm} ; \lambda_{\text {ex }} 320 \mathrm{~nm} / \lambda_{\text {em }} 410 \mathrm{~nm}\right)$ were employed. The aggregation kinetics was monitored using ThT at different time intervals. Aliquots of samples $(40 \mu \mathrm{M})$, incubated in the presence and in the absence of D-ribose, were mixed $(1: 1 \mathrm{v} / \mathrm{v})$ with buffer containing ThT at final concentration of $50 \mu \mathrm{M}$. Wavelengths $\left(\lambda_{\text {ex }} 450 \mathrm{~nm} / \lambda_{\text {em }} 482 \mathrm{~nm}\right.$ ) were employed. The fluorescence intensity was corrected by subtracting the emission intensity of ThT/D-ribose solutions.

\section{SDS-PAGE and Western blotting}

Aliquots of glycated protein samples were subjected to $15 \%$ SDS-PAGE using Bio-Rad (USA) electrophoresis equipment. For Western blot, the proteins were then transferred onto polyvinylidene difluoride membranes, and probed with anti-myoglobin or anti AGEs (EMD Millipore) antibody at a dilution of 1:1000 followed by goat anti-mouse horseradish peroxidase at a dilution of 1:2000. Immunoreactive bands were visualized using enhanced chemiluminescence (Pierce, USA).

\section{Spectroscopic measurements}

CD spectra were recorded at $25^{\circ} \mathrm{C}$ on a JascoJ-715 spectropolarimeter using thermostated quartz cells of $0.1 \mathrm{~cm}$. Spectral 
acquisition was taken at $0.2 \mathrm{~nm}$ intervals with a $4 \mathrm{sec}$ integration time and a bandwidth of $1.0 \mathrm{~nm}$. An average of three scans was obtained for all spectra. Photomultiplier absorbance did not exceed $600 \mathrm{~V}$ in the spectral region analyzed. Data were corrected for buffer contributions and smoothed using the software provided by the manufacturer (System Software version 1.00). All measurements were performed under nitrogen flow. The protein samples were diluted 1:2 before spectra acquisition.

\section{Transmission electron microscopy}

Fibril formation in the presence of D-ribose was monitored by transmission electron microscopy (EFTEM Lybra 120, Zeiss, Germany). Protein aliquots of $10 \mu \mathrm{L}$ were sampled from a protein solution of $40 \mu \mathrm{M}$, diluted $1: 10$ and deposited on 400mesh formvar-coated grid (Electron Microscopy Sciences, Hatfield, UK) and allowed to absorb for about $1 \mathrm{~min}$. The excess liquid was removed with filter paper. A drop of negative stain, $1 \%$ aqueous uranyl acetate made up fresh (Laurylab, Saint-Fons Cedex, France) was placed on the grid for $1 \mathrm{~min}$ and allowed to dry.

\section{Cell culture and incubation with protein aggregates}

NIH-3T3 cells (mouse fibroblasts, American Type Culture Collection) were cultured in Dulbecco's modified eagle's medium (DMEM)-high glucose supplemented with 10\% bovine calf serum and $3.0 \mathrm{mM}$ glutamine in a $5.0 \% \mathrm{CO}_{2}$ humidified environment at $37^{\circ} \mathrm{C}$. 50 units $/ \mathrm{mL}$ penicillin and $50 \mathrm{mg} / \mathrm{mL}$ streptomycin were added to the medium. The cells were plated at a density of
100,000 cells/well on 12-well plates in $1 \mathrm{~mL}$ of medium. After $24 \mathrm{~h}$, protein samples $(40 \mu \mathrm{M})$ were mixed $1: 1 \mathrm{v} / \mathrm{v}$ with cell media and incubated. Cells in culture medium without protein and in the presence of D-ribose served as control.

\section{MTT assay}

Cell viability was assessed as the inhibition of the ability of cells to reduce the metabolic dye 3-[4,5-dimethylthiazol-2-yl]-2,5diphenyltetrazolium bromide (MTT) to a blue formazan product [57]. After $24 \mathrm{~h}$ of incubation with protein samples, cells were rinsed with phosphate buffer solution (PBS). $100 \mathrm{~mL}$ of a stock MTT solution $(5 \mathrm{mg} / \mathrm{mL}$ in PBS) were then added to $900 \mu \mathrm{L}$ of DMEM without phenol red containing $10 \%$ bovine calf serum/ well, and incubation was continued at $37^{\circ} \mathrm{C}$ for an additional $3 \mathrm{~h}$. After removing the medium, cells were treated with isopropylalcohol-0.1 M HCl for $20 \mathrm{~min}$. Levels of reduced MTT were assayed by measuring the difference in absorbance at 570 and $690 \mathrm{~nm}$. Data are expressed as average percent reduction of MTT with respect to the control \pm S.D. from five independent experiments carried out in triplicate. For statistical analysis, we used a two-tailed Student's t test with unequal variance at a significance level of $5 \%$ unless otherwise indicated.

\section{Author Contributions}

Conceived and designed the experiments: IS GI. Performed the experiments: RM CI. Analyzed the data: CI RM. Contributed reagents/ materials/analysis tools: CI RM. Wrote the paper: CI IS GI.

\section{References}

1. Dobson CM (2003) Protein folding and misfolding. Nature 426: 884-890.

2. Luheshi LM, Dobson CM (2009) Bridging the gap: from protein misfolding to protein mis-folding diseases. FEBS Letters 583: 2581-2586.

3. Serpell LC, Sunde M, Benson MD, Tennent GA, Pepys MB, et al. (2000)) The protofilament substructure of amyloid fibrils. J Mol Biol 300: 1033-1039.

4. Kodali R, Wetzel R (2007) Polymorphism in the intermediates and products of amyloid assembly. Current Opinion in Structural Biology 17: 48-57.

5. Invernizzi G, Papaleo E, Sabate R, Ventura S (2012) Protein aggregation: mechanisms and functional consequences. Int J Biochem Cell Biol. 44: 15411554 .

6. Bucciantini M, Giannoni E, Chiti F, Baroni F, Formigli L, et al. (2002) Inherent toxicity of aggregates implies a common mechanism for protein misfolding diseases. Nature 416: 507-511.

7. Chiti F, Dobson CM (2006) Protein misfolding, functional amyloid, and human diseases. Annual Review of Biochemistry 75: 333-366.

8. Uversky VN (2010) Mysterious oligomerization of the amyloidogenic proteins. FEBS J 277: 2940-2953.

9. Stefani M (2012) Structural features and cytotoxicity of amyloid oligomers: Implication in Alzheimer's disease and other diseases with amyloid deposits. Progress in Neurobiology 99: 226-245.

10. Aggeli A, Nyrkova IA, Bell M, Harding R, Carrick L, et al. (2001) Hierarchical self-assembly of chiral rod-like molecules as a model for peptide beta-sheet tapes, ribbons, fibrils and fibers. PNAS USA 98: 11857-11862.

11. Guijarro JI, Sunde M, Jones JA, Campbell ID, Dobson CM (1998) Amyloid fibril formation by an SH3 domain. Proc Natl Acad Sci USA 95: 4224-4228.

12. Litvinovich SV, Brew SA, Aota S, Akiyama SK, Haudenschild C, et al. (1998) Formation of amyloid like fibrils by self association of a partially unfolded fibronectin type III module. J Mol Biol 280: 245-258.

13. Chiti F, Webster P, Taddei N, Clark A, Stefani M, et al. (1999) Designing conditions for in vitro formation of amyloid protofilaments and fibrils. Proc Natl Acad Sci USA 96: 3590-3594.

14. Vilasi S, Iannuzzi G, Portaccio M, Irace G, Sirangelo I (2008) Effect of trehalose on W7FW14F apomyoglobin and insulin fibrillization: new insight into inhibition activity. Biochemistry 47: 1789-1796.

15. Fandrich M, Forge V, Buder K, Kittler M, Dobson CM, et al. (2003) Myoglobin forms amyloid fibrils by association of unfolded polypeptide segments. Proc Natl.Acad.Sci USA 100: 15463-15468.

16. Sirangelo I, Malmo C, Casillo M, Mezzogiorno A, Papa M, et al. (2002) Tryptophanyl substitution in apomyoglobin determine protein aggregation and amyloid-like fibril formation at physiological pH. J Biol Chem 277: 4588745891.

17. Sirangelo I, Malmo G, Iannuzzi C, Mezzogiorno A, Bianco MR, et al. (2004) Fibrillogenesis and cytotoxic activity of the amyloid-forming apomyoglobin mutant W7FW14F. J Biol Chem 279: 13183-13189.

18. Iannuzzi C, Vilasi S, Portaccio M, Irace G, Sirangelo I (2007) Heme binding inhibits the fibrillization of amyloidogenic apomyoglobin and determines lack of aggregate cytotoxicity. Protein Sci 16: 507-516.

19. Iannuzzi C, Maritato R, Irace G, Sirangelo I (2013) Misfolding and amyloid aggregation of apomyoglobin. Int J Mol Sci 14: 14287-14300.

20. Malmo C, Vilasi S, Iannuzzi C, Tacchi S, Cametti C, et al. (2006) Tetracycline inhibits W7FW14F apomyoglobin fibril extension and keeps the amyloid protein in a pre-fibrillar, highly cytotoxic state. FASEB J 20: 346-347.

21. Ortore MG, Spinozzi F, Vilasi S, Sirangelo I, Irace G et al (2011) Timeresolved small-angle $\mathrm{x}$-ray scattering study of the early stage of amyloid formation of an apomyoglobin mutant. Phys Rev E Stat Nonlin Soft Matter Phys 84: 061904.

22. Vilasi A, Vilasi S, Romano R, Acernese F, Barone F, et al. (2013) Unraveling amyloid toxicity pathway in NIH3T3 cells by a combined proteomic and $1 \mathrm{H}$ NMR metabonomic approach. J Cell Physiol 228: 1359-1367.

23. Miyata T, Oda O, Inagi R, Iida Y, Araki N, et al. (1993) b2-Microglobulin modified with advanced glycation end products is a major component of hemodialysis-associated amyloidosis. J Clin Invest 92: 1243-1252.

24. Kikuchi S, Ogata A, Shinpo K, Moriwaka F, Fujii F, et al. (2000) Detection of an Amadori product, 1-hexitol-lysine, in the anterior horn of the amyotrophic lateral sclerosis and spinobulbar muscular atrophy spinal cord: evidence for early involvement of glycation in motoneuron diseases. Acta Neuropathol 99: 63-66.

25. Munch G, Luth HJ, Wong A, Arendt T, Hirsch E, et al. (2000) Crosslinking of alpha-synuclein by advanced glycation endproducts-an early pathophysiological step in Lewy body formation? J Chem Neuroanat 20: 253-257.

26. Dukic-Stefanovic S, Schinzel R, Riederer P, Munch G (2001) AGES in brainageing: AGE-inhibitors as neuroprotective and anti-dementia drugs? Biogerontology 2: 19-34.

27. Shults CW (2006) Lewy bodies. Proc Natl Acad Sci USA 103: 1661-1668.

28. Lyons TJ, Silvestri G, Dunn JA, Dyer DG, Baynes JW (1991) Role of glycation in modification of lens crystallins in diabetic and nondiabetic senile cataracts. Diabetes 40: 1010-1015.

29. McCance DR, Dyer DG, Dunn JA, Bailie KE, Thorpe SR, et al. (1993) Maillard reaction products and their relation to complications in insulin-dependent diabetes mellitus. J Clin Invest 91: 2470-2478.

30. Miyata T, van Ypersele de Strihou G, Kurokawa K, Baynes JW (1999) Alterations in nonenzymatic biochemistry in uremia: origin and significance of "carbonyl stress" in long-term uremic complications. Kidney Int 55: 389-399. 
31. Day JF, Thorpe SR, Baynes JW (1979) Nonenzymatically glucosylated albumin. In vitro preparation and isolation from normal human serum. J Biol Chem 254: 595-597.

32. Monnier VM, Nagaraj RH, Portero-Otin M, Glomb M, Elgawish AH, et al. (1996) Structure of advanced Maillard reaction products and their pathological role. Nephrol Dial Transplant 11: 20-26.

33. Necula M, Kuret J (2004) Pseudophosphorylation and glycation of Tau protein enhance but do not trigger fibrillization in vitro. J Biol Chem 279: 49694-49703.

34. Obrenovich ME, Monnier VM (2004) Glycation stimulates amyloid formation. Sci. Aging Knowledge Environ 2004: pe3.

35. Vitek MP, Bhattacharya K, Glendening JM, Stopa E, Vlassara H, et al. (1994) Advanced glycation end products contribute to amyloidosis in Alzheimer disease. Proc Natl Acad Sci USA 91: 4766-4770.

36. Shaikh S, Nicholson LF (2008) Advanced glycation end products induce in vitro cross-linking of alpha-synuclein and accelerate the process of intracellular inclusion body formation. J Neurosci Res 86: 2071-2082.

37. Woltjer RL, Maezawa I, Ou JJ, Montine KS, Montine TJ (2003) Advanced glycation endproduct precursor alters intracellular amyloid-beta/A beta PP carboxy-terminal fragment aggregation and cytotoxicity. J Alzheimers Dis 5: $467-476$.

38. Oliveira LM, Lages A, Gomes RA, Neves H, Família C, et al, (2011) Insulin glycation by methylglyoxal results in native-like aggregation and inhibition of fibril formation. BMC Biochemistry 12: 41 .

39. Kong FL, Cheng W, Chen J, Liang Y (2011) d-Ribose glycates $\beta(2)$ microglobulin to form aggregates with high cytotoxicity through a ROSmediated pathway. Chem Biol Interact 194: 69-78.

40. Wei Y, Chen L, Chen J, Ge L, He R (2009) Rapid glycation with D-ribose induces globular amyloid-like aggregations of BSA with high cytotoxicity to SHSY5Y cells. BMC Cell Biol 10: 10.

41. Chen L, Wei Y, Wang X, He R (2009) D-Ribosylated Tau forms globular aggregates with high cytotoxicity. Cell Mol Life Sci 66: 2559-2571.

42. Chen L, Wei Y, Wang X, He R (2010) Ribosylation rapidly induces alphasynuclein to form highly cytotoxic molten globules of advanced glycation end products. PLoS One 5: e9052.

43. Nelson DL, Cox MM (2004) Lehninger Principle of Biochemistry 3rd ed., Worth Publishers, New York, America. 297-324.

44. Wei Y, Han CS, Zhou J, Liu Y, Chen L, et al. (2012) D-ribose in glycation and protein aggregation. BBA 1820: 488-494.

45. Johansen MB, Kiemer L, Brunak S (2006) Analysis and prediction of mammalian protein glycation. Glycobiology 16: 844-853.
46. Munanairi A, O'Banion SK, Gamble R, Breuer E, Harris AW, et al. (2007) The multiple Maillard reactions of ribose and deoxyribose sugars and sugar phosphates. Carbohydr Res 342: 2575-2592.

47. Levine H, III (1993) Thioflavine T interaction with synthetic Alzheimer's disease beta-amyloid peptides: detection of amyloid aggregation in solution. Protein Sci 2: 404-410.

48. Naiki H, Higuchi K, Hosokawa M, Takeda T (1989) Fluorometric determination of amyloid fibrils in vitro using the fluorescent dye, thioflavin T1. Anal Biochem 177: 244-249.

49. Cussimanio BL, Booth AA, Todd P, Hudson BG, Khalifah RG (2003) Unusual susceptibility of heme proteins to damage by glucose during non-enzymatic glycation. Biophysical Chemistry 105: 743-755.

50. Bokiej M, Livermore AT, Harris AW, Onishi AC, Sandwick RK (2011) Ribose Sugars Generate Interrnal Glycation Cross-links in Horse Heart Myoglobin. Biochem Biophys Res Commun. 407: 191-196.

51. Infusini G, Iannuzzi C, Vilasi S, Birolo L, Pagnozzi D, et al. (2012). Resolution of the effects induced by $\mathrm{W} \rightarrow \mathrm{F}$ substitutions on the conformation and dynamics of the amyloid-forming apomyoglobin mutant W7FW14F. Eur Biophys J 41: 615-627.

52. Infusini G, Iannuzzi G, Vilasi S, Maritato R, Birolo L, et al. (2013) W-F Substitutions in Apomyoglobin Increase the Local Flexibility of the N-terminal Region Causing Amyloid Aggregation: A H/D Exchange Study. Protein Pept Lett 20: 898-904.

53. Stefani M, Dobson CM (2003) Protein aggregation and aggregate toxicity: new insights into protein folding, misfolding diseases and biological evolution. J Mol Med 81: 678-699.

54. Li J, Liu D, Sun L, Lu Y, Zhang Z (2012) Advanced glycation end products and neurodegenerative diseases: Mechanisms and perspective. Journal of the Neurological Sciences 317: 1-15.

55. Prischi F, Pastore C, Carroni M, Iannuzzi C, Adinolfi S, et al. (2010) Of the vulnerability of orphan complex proteins: the case study of the E. coli IscU and IscS proteins. Protein Expr Purif 73: 161-166.

56. Yan R, Konarev PV, Iannuzzi C, Adinolfi S, Roche B, et al. (2013) Ferredoxin competes with bacterial frataxin in binding to the desulfurase IscS. J Biol Chem 288: $24777-24787$.

57. Hansen MB, Nielsen SE, Berg K (1989) Re-examination and further development of a precise and rapid dye method for measuring cell growth/ cell kill. J Immunol Methods 119: 203-210.

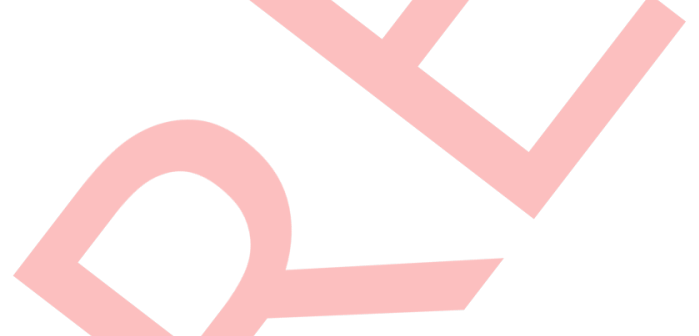

